\title{
SIKAP MASYARAKAT HUKUM ADAT BALI TERHADAP PUTUSAN MK NO. 46/PUU-VIII/2010 TERKAIT KEDUDUKAN ANAK LUAR KAWIN ${ }^{1}$
}

\author{
Oleh : \\ Ni Nyoman Sukerti (nyomansukerti10@yahoo.com) \\ I Gst. Ayu Agung Ariani (oka.ariani@yahoo.com) \\ I Ketut Sudantra (sudantra01@yahoo.co.id) ${ }^{2}$
}

\begin{abstract}
This study aimed to determine the knowledge of indigenous people of Bali against the Constitutional Court No.46 / PUU-VII / 2010, meaning the Constitutional Court ruling related to the child outside the mating position, to identify and analyze the attitudes of indigenous communities Bali on the discharge of the Constitutional Court. This study is an empirical law with non-doctrinal approach (socio legal research).

The results showed that indigenous people in general do not yet know Bali Court Decision No.46 / PUU-VII / 2010 was. Meaning beyond mating gives children the same rights as children born within marriage. Balinese people's attitudes related to this decision, can be classified into two: 1. Most accept the decision of the reason; children outside the mating status to clear, the mother can claim responsibility for the biological father of the child, the child is no longer despised in the family and society. 2. small Sebagain reject reason; children outside mating can cause problems in inheritance in biological father, contrary to the customary law of Bali, girls may prefer not to marry. The attitude of the indigenous peoples of Bali pros and cons of the legal culture of society.

Conclusion: Its meaning is to give children the right to marry outside the same as children born within marriage. Balinese customary law community in general have not been aware of the Constitutional Court. Balinese people's attitudes towards the Constitutional Court ruling pro and cons.
\end{abstract}

Keywords: constitutional court ruling, beyond mating child, ttitude indigenous people of Bali.

\section{PENDAHULUAN}

\subsection{Latar Belakang Masalah}

Negara Indonesia sebagai negara yang sedang berkembang sudah berumur 70

Karya ilmiah ini merupakan hasil penelitian di biayai dari dana Dipa BLU Program Studi Magister (S2) Ilmu Hukum PPS UNUD dengan SK direktur No.750/UN.14.4/KU/2015 tanggal 29 Mei 2015 telah dipresentasikan dalam seminar/FGD di Program Magister (2) Ilmu Hukum

2 Para penulis dosen di Program Studi (S2) Ilmu Hukum dan Fakultas Hukum UNUD. tahun. Pada umurnya yang 70 tahun tersebut sudah cukup banyak peraturan perundangundangan yang berhasil dibuatnya. Namun demikian dalam hukum keluarga dan hukum waris belum berhasil dibuatnya. Jadi dalam hukum keluarga dan hukum waris belum ada hukum yang berlaku secara nasional sehingga masih berlaku pluralisme hukum.

Hukum keluarga dan hukum waris yang berlaku di Indonesia masih bersifat pluralisme hukum. Artinya dalam bidang 
hukum keluarga dan hukum waris berlaku lebih dari satu sistem hukum. Adapun sistem hukum tersebut yaitu sistem hukum adat, hukum islam dan hukum perdata barat atau Kitab Undang-Undang Hukum Perdata (KUHPerdata). Masih berlakunya pluralisme hukum disebabkan belum mampunya negara atau pemerintah membuat unifikasi hukum dalam dua lapangan hukum tersebut. Sehubungan dengan hal tersebut, dalam kajian ini difokuskan pada hukum adat yakni hukum adat Bali.

Dalam pewarisan ahli waris merupakan salah satu unsur esensiil untuk dapat terjadinya pewarisan oleh karena itu dalam penentuan ahli waris erat kaitannya dengan sistem kekeluargaan yang dianut oleh masyarakat di Indonesia. Pada umumnya kehadiran seorang anak dalam sebuah keluarga sangat di dambakan, apabila dalam sebuah keluarga kecil atau keluarga batih, ketidakhadiran seorang anak dapat menggoyahkan pondasi rumah tangga suatu keluarga. Kehadiran seorang anak mempunyai peranan yang sangat penting dalam suatu perkawinan, karena tujuan perkawinan selain membina rumah tangga yang bahagia dan sejahtera adalah untuk melanjutkan keturunan, agar tidak terjadi kepunahan (camput). Begitu pentingnya kehadiran seorang anak dalam sebuah keluarga, terlebih anak laki-laki yang di Bali dipercaya sebagai penyelamat roh leluhur dari siksaan neraka. Tiadanya anak dalam keluarga (perkawinan), dapat dipakai alasan oleh sang suami untuk melakukan poligami dan bahkan ada kalanya juga dipakai alasan untuk menceraikan sang istri, walaupun belum tentu sang istri yang mandul.

Anak-anak yang lahir dari perkawinan yang sah orang tuanya disebut anak sah, sedangkan anak yang lahir tanpa ada perkawinan orang tuanya disebut anak tidak sah atau anak luar kawin. Antara anak sah dan anak luar kawin sebagai keturunan mempunyai kedudukan yang tidak sama dalam keluarga. Seseorang sebagai keturunan mempunyai hubungan darah dengan orang menurunkannya. Di samping mempunyai hubungan darah dans juga mempunyai hubungan hukum dengan orang yang menurunkannya. Sehubungan dengan tersebut Djojodiguno dalam Surojo Wignjodipuro, mengatakan bahwa keturunan adalah ketunggalan leluhur, artinya ada perhubungan darah antara orang seorang dan dan orang lain. Dua orang atau lebih yang mempunyai hubungan darah, jadi yang tunggal leluhur, adalah keturunan yang seorang dari yang lain. ${ }^{3}$

Mencermati pendapatdariDjojodiguno tersebut, dimana keturunan adalah orang yang mempunyai hubungan darah dengan orang yang menurunkannya. Ini berarti orang yang dimaksudkan adalah laki-laki dan perempuan yang menyebabkan keturunan itu ada sudah melangsungkan perkawinan. Lantas bagaimana manakala laki-laki dan perempuan yang menyebabkan keturunan itu tidak melangsungkan perkawinan? Kalau dicermati lebih dalam, walaupun tidak ada perkawinan antara laki-laki dan perempuan yang menyebabkan seorang keturunan (anak) itu lahir tetap sang anak mempunyai hubungan darah, tetapi sang anak tidak mempunyai hubungan hukum dengan lakilaki yang menyebabkan ia lahir. Dalam kaitan penelitian ini, lantas bagaimana hubungan hukum anak yang bersangkutan

Surojo Wignjodipuro, Pengantar Dan Asas-Asas Hukum Adat, Gunung Agung, Jakarta, 1967, hlm.108. 
dengan laki-laki yang menyebabkan dia lahir. Sebuhungan dengan hal tersebut maka menjadi penting untuk melakukan penelitian berkenaan dengan kedudukan hukum anak luar kawin setelah keluarnyan putusan MK No.46/PUU-VIII/2010.

\subsection{Rumusan Masalah.}

Bertitik tolak dari latar belakang tersebut di atas, dirumuskan permasalahan sebagai berikut:

1. Apa makna Putusan MK No. No.46/ PUU-VIII/2010 terhadap kedudukan anak luar kawin di dalam Hukum Adat Bali?

2. Bagaimana sikap masyarakat hukum adat Bali terhadap Putusan MK No. No.46/PUU-VIII/2010 sehubungan dengan kedudukan anak luar kawin?

\section{METODE PENEITIAN}

\subsection{Jenis dan Sifat Penelitian}

Penelitian tentang sikap masyarakat hukum adat Bali terhadap Putusan MK No. No.46/PUU-VIII/2010 tentang Uji Material Undang-Undang Perkawinan sehubungan kedudukan anak luar kawin adalah merupakan penelitian hukum empiris dimana data lapangan sebagai data primer. Penelitian ini tidak akan menguji hipotesis, akan tetapi menggali informasi sebanyak mungkin sehubungan dengan sikap masyarakat hukum adat Bali terhadap keluarnya Putusan MK No.46/PUU-VIII/2010 sehubungan dengan kedudukan anak luar kawin tersebut. Oleh karenanya penelitian ini bersifat deskritif, yaitu menggambarkan atau menjelaskan sikap masyarakat hukum adat Bali terhadap Putusan MK sehubungan dengan kedudukan anak luar kawin.

\section{Jenis dan Sumber Data}

Dalam penelitian ini data yang digali dan dikumpulkan adalah berupa data primer dan data sekunder. Data primer diperoleh data yang digali di lapangan yakni di wilayah Kota Denpasar. Sebagai lokasi penelitian ditentukan secara purposif dengan dasar pertimbangan bahwa di Kota Denpasar yang sekaligus sebagai pusat Pemerintahan Propinsi Bali, dimana kondisi masyarakatnya relatif lebih maju dengan tingkat pendidikan lebih tinggi dibandingkan dengan daerah lainya di Bali. Penentuan informan responden ditentukan dengan teknik snow ball (bola salju) dan yang dipilih adalah tokoh masyarakat, tokoh agama, dan warga masyarakat.

Data sekunder diperoleh dari penelusuran bahan-bahan tertulis atau dokumen-dokumen yang memuat informasi sehubungan dengan anak yang lahir di luar perkawinan kedua orang tuanya.

\subsection{Teknik Pengumpulan Data.}

Untuk mendapatkan data yang diperlukan, teknik pengumpulan data yang digunakan dalam penelitian ini adalah teknik wawancara yang berpedoman pada pedoman pertanyaan (interview guide).

\subsection{Teknik Pengumpulan Data}

Pengolahan dan analisis data dilakukan dengan menggunakan metode yang bersifat kualitatif yang dilengkapi dengan analisis situasional. Metode ini akan dapat menunjukan tentang sikap masyarakat hukum Adat Bali terhadap Putusan MK No.46/PUU-VIII/2010 tentang Uji Materiil Undang-Undang Perkawinan terkait kedudukan anak luar kawin. 


\section{HASILDAN PEMBAHASAN}

\subsection{Tinjauan Umum Tentang Macam-} Macam Anak Dalam Hukum Adat.

Secara umum dalam hukum adat dikenal dua jenis anak yaitu anak yang lahir dalam perkawinan yang disebut anak syah dan anak yang lahir di luar perkawinan yang disebut anak tidak syah. Anak yang lahir dalam perkawinan juga banyak macamnya seperti anak kandung, anak tiri, anak angkat dan anak piara, sementara anak yang lahir di luar perkawinan ada disebut anak haram dan anak haram jadah. Kalau dalam masyarakat Bali anak yang lahir di luar perkawinan ada dua macam yaitu ada yang disebut anak bebinjat, ada yang disebut anak astra. Masing-masing anak tersebut di atas mempunyai kedudukan dan hak tidak sama dalam keluarganya.

Anak bebinjat adalah anak lahir yang tanpa ada perkawinan dari orang tuannya dimana si ibu tidak dapat menunjukan lakilaki mana yang menyebabkan dirinya hamil dan melahirkan anak karena laki-laki yang mengaulinnya lebih dari satu orang. Oleh karenaitudisebutanakbebinjatartinyaibunya jahat. Sementara anak astra adalah anak yang lahir di luar perkawinan orang tuanya, hal itu terjadi dikarenakan sesuatu hal sehingga belum bisa melakukan perkawinan namun anaknya keburu lahir. Anak astra adalah anak dari perempuan kebanyakan (common people) dengan laki-laki dari golongan tri wangsa. Anak astra diketahui bapaknya dan biasanya anak tersebut diberikan biaya hidup oleh ayah biologisnya tetapi anak tersebut mengikuti garis keturunan ibunya.

Mengenai anak yang lahir di luar perkawinan dapat dilakukan upaya untuk menghindari celaan dari masyarakat dan anak tersebut mempunyai status dan kedudukan yang jelas dalam keluarga dan masyarakat. Terkait dengan hal tersebut Sukerti mengemukakan bahwa di Kabupaten Tabanan, anak yang lahir diluar perkawinan biasanya diangkat anak oleh saudara ibunya atau oleh orang tua ibunya (kakek-nenek) anak yang bersangkutan. ${ }^{4}$

Anak kandung adalah anak yang mempunyai kedudukan yang sangat penting dalam setiap somah (gezin) masyarakat adat. $^{5}$ Anak sebagai penerus generasi dan wadah (tempat tumpuan) dimana semua harapan orang tuannya dikemudian hari ditumpahkan, sebagai pelindung orang tuannya dimana secara fisik orang tuannya tidak mampu bekerja lagi. Sementara anak tiri adalah anak orang lain yang ada dalam suatu keluarga. Mengenai anak tiri sebenarnya dapat dilihat dari sudut siapa anak tersebut dilihat dan dari sistem kekeluargaan yang dianutnya. Kalau dilihat dari sudut si ayah pada masyarakat patrilineal tidak dikenal anak tiri karena dalam masyarakat patrilineal adalah semua masuk dalam garis bapaknya berapapun ibunya. Kalau dilihat dari sudut si ibu baru dikenal anak tiri, akan tetapi tidak berpengaruh dalam keluarga dan pewarisan karena semua anak laki-laki mempunyai hak waris terhadap harta kekayaan orang tuanya, kecuali anak yang bersangkutan hak warisnya telah gugur.

Pada masyarakat matrilineal masalah anak tiri adalah merupakan kebalikan dari masyarakat yang patrilineal. Sementara pada masyarakat parental, anak tiri dapat dilihat

Ni Nyoman Sukerti, "Kedudukan Hukum Anak Luar Kawin di Kabupaten Tabanan", Laporan Penelitian, Fakultas Hukum, Universitas Udayana, Denpasar, 1990, hlm.21.

Tolib Setiady, Intisari Hukum Adat Indonesia (Dalam Kajian Kepustakaan), Alfabeta, Bandung, 2008, hlm.208. 
dari sudut ayah dan juga ibu karena pada masyarakat parental ada kalanya masingmasing membawa anak dalam perkawinan. Dalam mewaris anak tiri tetap mewaris pada orang tua kandungnya. Anak angkat adalah anak orang lain yang diangkat anak oleh suatu keluarga. Mengenai anak angkat, ini ada perbedaan dalam pewarisan antara masyarakat patrilineal dengan masyarakat parental. Pada masyarakat patrilineal anak angkat mempunyai kedudukan yang sama dengan anak kandung dalam keluarga dan pewarisan seperti di Bali ini. Anak angkat adalah ahli waris penuh pada keluarga angkatnya sementara pada masyarakat parental seperti di Jawa anak angkat hanya mempunyai hak waris terhadap harta gono gini orang tua angkatnya sementara terhadap harta-harta lainnya anak angkat sama sekali tidak berhak. Sementara masyarakat matrilineal seperti Minangkabau tidak mengenal lembaga pengangkatan anak.

Anak piara adalah anak orang lain yang dipelihara oleh suatu keluarga karena alasan ekonomi, ini sifatnya hanya sementara karena setelah anak yang bersangkutan dewasa dan bisa mencari penghidupan sendiri anak tersebut akan dikembalikan kepada orang tua kandungnya. Jadi terhadap anak piara tidak ada hubungan dengan masalah pewarisan pada keluarga yang memeliharanya. Perbuatan memelihara anak orang lain tersebut dilakukan sebatas belas kasihan saja.

Jadi dalam kaitan bermacam-macam anak tersebut di atas mempunyai kedudukan yang tidak sama dalam keluarga dan pewarisan, hal itu tergantung dari sistem kekeluargaan yang berlaku dalam masyarakat anak-anak tersebut.

\subsection{Kedudukan Anak Luar Kawin Pasca Keluarnya Putusan MK No.46/PUU- VIII/2010.}

Masalah anak yang lahir di luar perkawinan yang menurut hukum adat hanya mempunyai hubungan dengan ibunya saja, akan tetapi dalam Undang-Undang Perkawinan Pasal 43 ayat 1 disebutkan bahwa anak yang lahir di luar perkawinan hanya mempunyai hubungan perdata dengan ibunya dan keluarga ibunya.

Mencermati anak luar kawin sebagaimana telah disebutkan di atas menurut hukum adat hanya mempunyai hubungan perdata dengan ibunya sementara UndangUndang Perkawinan menyebut dimana anak luar kawin di samping mempunyai hubungan perdata dengan ibunya juga dengan keluarga ibunya, maka lingkup undang-undang lebih luas. Terkait dengan hal tersebut hukum adat harus tunduk pada hukum negara atau hukum nasional dalam hal ini Hukum Perkawinan Nasional. Hal tersebut sesuai dengan Pasal 28 B ayat 2 UUD RI 1945. Adapun ketentuan pasal tersebut sebagai berikut: setiap anak berhak atas kelangsungan hidup, tumbuh, dan berkembang serta berhak atas perlindungan dari kekerasan dan diskriminasi (hasil amandemen kedua). Intinya seorang anak harus hidup aman dan nyaman tanpa memandang anak tersebut lahir dalam perkawinan atau lahir di luar perkawinan orang tuannya. Ini berarti anak yang lahir di luar perkawinan harus diperhitungkan bidang kepedataannya pada keluarga ibunya.

Hukum Perkawinan Nasional sudah cukup lama berlaku namun dalam hal anak luar kawin mempunyai hubungan keperdataan dengan keluarga ibunya terutama pada masyarakat patrilineal sangat sulit diterimanya. Jadi masalah anak luar 
kawin tetap masih dipandang negatif atau cébela mata oleh keluarga dan bahkan masyarakat.

Jadi dalam kaitan adanya macammacam anak seperti tersebut di atas mempunyai kedudukan yang tidak sama dalam keluarga dan pewarisan, hal itu tergantung dari sistem kekeluargaan yang berlaku dalam masyarakat anak-anak tersebut.

Khusus mengenai kedudukan anak luar kawin pasca keluarnya Putusan Mahkamah Konstitusi (MK) No.46/PUUVIII/2010 tentang Uji Materiil UndangUndang Perkawinan telah mengalami perubahan. Hal mana di dalam Putusan MK tersebut dalam pertimbangan hukumnya menyatakan bahwa ... tidak tepat dan tidak adil manakala hukum menetapkan bahwa anak yang lahir dari suatu kehamilan karena hubungan seksual di luar perkawinan hanya memiliki hubungan dengan perempuan yang sebagai ibunya. Adalah tidak tepat dan tidak adil pula jika hukum membebaskan laki-laki yang melakukan hubungan seksual yang menyebabkan kehamilan dan kelahiran anak tersebut dari tanggung jawabnya sebagai seorang bapak dan bersamaan dengan itu hukum meniadakan hak-hak anak terhadap lelaki tersebut sebagai bapak ... ${ }^{6}$

Makna dari Putusan MK tersebut adalah memberi hak yang sama terhadap anak luar kawin dengan anak-anak yang lahir dalam perkawinan yang syah. Ini berarti akan menimbulkan masalah karena melegalkan hubungan seksual di luar perkawinan dan bahkan dapat berakibat merebaknya

D.Y. Witanto, Hukum Keluarga Hak Dan Kedudukan Anak Luar Kawin Pasca Keluarnnya Putusan MK Tentang Uji Materiil Undang-Undang Perkawinan, Prestasi Pustaka Publisher, Jakarta, 2012, hlm.242. hubungan sek bebas yang tidak jauh berbeda dengan binatang.

Terhadap Putusan MK tersebut, hasil penelitian menunjukan bahwa terdapat perbedaan pendapat dari warga masyarakat hukum adat yang mana dapat digolongan menjadi dua kelompok yaitu kelompok yang menerima dan kelompok menolak Putusan MK tersebut. Kelompok yang menerima Putusan MK tersebut adalah sebagian besar dari warga masyarakat hukum adat Bali yang diteliti, sementara kelompok yang menolak putusan tersebut adalah sebagian kecil dari warga masyarakat hukum adat Bali yang diteliti. Kelompok yang menerima Putusan MK memberikan beberapa alasan yaitu anak luar kawin statusnya menjadi jelas, si ibu dapat menuntut tanggung jawab terhadap ayah biologis si anak, si anak tidak lagi dipandang hina dan rendah dalam keluarga dan masyarakat. Kelomopk yang menolak Putusan MK tersebut yang merupakan sebagian kecil dari warga masyarakat memberikan alasannya: anak luar kawin dapat menimbulkan masalah dalam pewarisan pada bapak biologisnya, bertentangan dengan hukum adat Bali, anak perempuan bisa lebih memilih tidak kawin.

Sikap masyarakat hukum adat Bali sehubungan dengan keluarnya Putusan MK adalah ada yang pro dan kontra. Hal tesebut tiada lain adalah merupakan budaya hukum masyarakat adat Bali terhadap hukum yang diberlakukan. Budaya hukum (legal culture) menurut L.M. Friedman, meliputi ide-ide, sikap-sikap, kepercayaan, nilai-nilai, harapan, dan pandangan tentang hukum ${ }^{7}$. Sementara Hilman Hadikusuma,

Lawrence M. Friedman, The Legal System : A Social Science Perspective, New York: Russel, 1975, p.7. 
menguraikan budaya hukum adalah tanggapan yang bersifat penerimaan atau penolakan terhadap suatu peristiwa hukum. Ia merupakan sikap dan prilaku manusia terhadap masalah hukum yang terbawa ke dalam masyarakat ${ }^{8}$. Budaya hukum adalah merupakan salah satu unsur hukum dalam suatu sistem hukum.

\section{KESIMPULAN DAN SARAN}

\subsection{Kesimpulan}

Dari keseluruhan uraian atau paparan tersebut di atas dapat disimpulkan sebagai berikut :

4.1.1 Putusan MK No.46/PUU-VIII/2010 tentang Uji Materiil Undang-Undang Perkawinan adalah mempunyai makna memberikan hak yang sama kepada anak luar kawin dengan anak yang lahir dalam perkawinan yang syah.

4.1.2 Sikap masyarakat hukum adat Bali terkait Putusan MK tersebut dapat digolonganmenjadiduakelompokyaitu kelompok yang menerima dan yang menolak. Kelompok yang menerima memberi alasan yaitu anak luar kawin statusnya menjadi jelas, si ibu dapat menuntut tanggung jawab terhadap ayah biologis si anak, si anak tidak lagi dipandang hina dan rendah dalam keluarga dan masyarakat. Sementara yang menolak memberi alasan yaitu anak luar kawin dapat menimbulkan masalah dalam pewarisan pada bapak biologisnya, bertentangan dengan hukum adat Bali, anak perempuan bisa lebih memilih tidak kawin.

Hilman Hadikusuma, Antropologi Hukum Indonesia, Alumni, Bandung, 1986, hlm.52.

\subsection{Saran}

Melalui penelitian ini disarankan kepada masyarakat adat Bali agar lebih hatihati menyikapi makna dari Putusan MK No.46/PUU-VIII/2010 tentang Uji Materiil Undang-Undang Perkawinan tersebut karena hal itu dapat melegalkan persinahan dan bisa merubah pandangan dari warga masyarakat adat Bali bahwa tidak perlu adanya perkawinan. Kalau hal tersebut menjadi lumrah dan tidak dipandang hina maka pada akhirnya manusia dapat dikatakan tidak berbeda dengan binatang.

\section{DAFTAR PUSTAKA}

Friedman, Lawrence M, 1975, The Legal System : A Social Science Perspective, New York: Russel.

Hilman Hadikusuma, Hilman, 1986, Antropologi Hukum Indonesia, Alumni, Bandung.

Setiady, Tolib, 2008, Intisari Hukum Adat Indonesia (Dalam Kajian Kepustakaan), Alfabeta, Bandung.

Sukerti, Ni Nyoman, 1990, "Kedudukan Hukum Anak Luar Kawin Di Kabupaten Tabanan", Laporan Penelitian, Fakultas Hukum, Unud.

Wignjodipuro, Surojo, 1967, Pengantar Dan Asas-Asas Hukum Adat, Gunung Agung, Jakarta.

Witanto, D.Y. 2012, Hukum Keluarga Hak Dan Kedudukan Anak Luar Kawin Pasca Keluarnya Putusan MK Tentang Uji Materiil U U Perkawinan, Prestasi Pustaka Publisher, Jakarta. , 2002, Undang-Undang Negara Republik Indonesia 1945, Hasil Amandemen, Sinar Grafika, Yakarta. 2004, Himpunan Peraturan Perundang-Undangan Perkawinan, Lintang Pustaka, Yogyakarta. 